\title{
Preconditioning with carbon monoxide inhalation promotes retinal ganglion cell survival against optic nerve crush via inhibition of the apoptotic pathway
}

\author{
RUOBING WANG $^{1 *}$, ZELI CHEN $^{2 *}$, JIANGCHUN WU $^{1}$, FANGZHOU XIA $^{1}$, \\ QINGLEI SUN ${ }^{1}$, AIJUN SUN ${ }^{3}$ and LIN LIU ${ }^{1}$
}

${ }^{1}$ Department of Ophthalmology, Renji Hospital, School of Medicine, Shanghai Jiao Tong University, Shanghai 200127;
${ }^{2}$ Department of Ophthalmology, Daping Hospital and Research Institute of Surgery, Third Military Medical University,
Chongqing 400042; ${ }^{3}$ Department of Anatomy, Second Military Medical University, Shanghai 200433, P.R. China

Received February 7, 2017; Accepted September 27, 2017

DOI: $10.3892 / \mathrm{mmr} .2017 .7990$

\begin{abstract}
Optic neurodegeneration, in addition to central nervous trauma, initiates impairments to neurons resulting in retinal ganglion cell (RGC) damage. Carbon monoxide (CO) has been observed to elicit neuroprotection in various experimental models. The present study investigated the potential retinal neuroprotection of preconditioning with $\mathrm{CO}$ inhalation in a rat model of optic nerve crush (ONC). Adult male Sprague-Dawley rats were preconditioned with inhaled $\mathrm{CO}(250 \mathrm{ppm})$ or air for $1 \mathrm{~h}$ prior to ONC. Animals were euthanized at 1 or 2 weeks following surgery. RGC densities were quantified by hematoxylin and eosin (H\&E) staining and FluoroGold labeling. Visual function was measured via flash visual evoked potentials (FVEP). Terminal deoxynucleotidyl transferase dUTP nick end labeling (TUNEL) staining, and caspase- 9 and caspase- 3 activity in the retinas, were assessed at 2 weeks post-ONC. The RGC density of $\mathrm{CO}+$ crush rats was significantly increased compared with that of the corresponding crush-only rats at 2 weeks (survival rate, 66.2 vs. $48.2 \%$ as demonstrated by $\mathrm{H} \& \mathrm{E}$ staining, $\mathrm{P}<0.01$; and 67.6 vs. $37.6 \%$ as demonstrated by FluoroGold labeling, $\mathrm{P}<0.05$ ). FVEP measures indicated a significantly better-preserved latency and amplitude of the P1 wave in the $\mathrm{CO}+$ crush rats compared with the crush-only rats. The TUNEL assays demonstrated fewer apoptotic cells in the $\mathrm{CO}+$ crush group
\end{abstract}

Correspondence to: Professor Lin Liu or Dr Ruobing Wang, Department of Ophthalmology, Renji Hospital, School of Medicine, Shanghai Jiao Tong University, 160 Pujian Road, Shanghai 200127, P.R. China

E-mail: liulin1962rj@126.com

E-mail: adawrb@126.com

*Contributed equally

Key words: carbon monoxide, preconditioning, neuroprotection, optic nerve crush, retinal ganglion cell compared with the crush-only group, accompanied by the suppression of caspase- 9 and caspase- 3 activity. The results of the present study suggested that inhaled $\mathrm{CO}$ preconditioning may be neuroprotective against ONC insult via inhibition of neuronal apoptosis.

\section{Introduction}

The optic nerve is an extension of the central nervous system (CNS). CNS trauma causes damage to neurons including inflammation, neuronal apoptosis and functional recovery inhibition $(1,2)$. The impairment of the optic nerve results in degeneration of the axon and death of retinal ganglion cells (RGCs), as they convey visual signals from the retina along their axons through the optic nerve to the brain, and even irreversible loss of vision $(3,4)$. Optic nerve crush $(\mathrm{ONC})$ is a well-established model of axonal injury to the optic nerve, due to its accessibility, stability and reproducibility $(5,6)$. Following ONC, the injured RGCs suffer from either early necrosis or delayed apoptotic death (7), and cellular apoptosis mainly occurred within the first 2 weeks $(8,9)$.

Carbon monoxide (CO) is a colorless and odorless gas that has been known to be a toxic molecule for centuries, due to its potent affinity to hemoglobin which results in hypoxia (10). However a number of studies have demonstrated that low or near-physiological doses of CO may have anti-inflammatory (11), anti-proliferative (12) and anti-apoptotic (13) properties, and neuroprotective effects (14). In optic neuropathy, Biermann et al (15) demonstrated that preconditioning with CO may protect RGCs from retinal ischemic/reperfusion injury. A previous study indicated that inhaled $\mathrm{CO}$ exerts neuroprotective effect against ONC (16). The present study investigated the effects of preconditioning with $\mathrm{CO}$ inhalation on ONC-induced RGC loss and the possible mechanisms.

\section{Materials and methods}

Animals and groups. A total of 108 adult male Sprague-Dawley rats (6 weeks old, 150-200 g) obtained from the experimental animal center of Shanghai Jiao Tong University (certification: 
SCXK Shanghai 2012-0002) were used in the experiments. The animals were raised in 20 cages in a temperature $\left(23^{\circ} \mathrm{C}\right)$ and humidity $(50 \%)$ controlled room with a 12-h light/dark cycle. Standard animal chow and water were freely available. The experiments were performed according to the Guide for the Care and Use of Laboratory Animals recommended by the National Institutes of Health (Bethesda, MD, USA), and were approved by the Ethics Committee for Animal Experimentation of Shanghai Jiao Tong University (Shanghai, China). Animals were randomly divided into three groups of $36:$ i) $\mathrm{CO}+$ crush group, in which ONC was performed on the right eyes immediately following exposure to $250 \mathrm{ppm} \mathrm{CO}$ for $1 \mathrm{~h}$; ii) crush group, in which only ONC was performed on the right eye of each rat; and iii) sham group, in which sham surgery was performed on the right eye. When the rats had been anesthetized with $10 \%$ chloral hydrate solution $(400 \mathrm{mg} / \mathrm{kg})$, the eyeballs were rapidly removed in $2 \mathrm{~min}$. $\mathrm{CO}_{2}$ euthanasia $(5 \mathrm{l} / \mathrm{min}$ ) was subsequently administered to the rats. Other procedures, including ONC, flash visual evoked potential (FVEP) analysis and FluoroGold intravitreous injection, were performed under deep anesthesia with $10 \%$ ketamine $(95 \mathrm{mg} / \mathrm{kg})$ and $2 \%$ xylazine $(7 \mathrm{mg} / \mathrm{kg})$, injected intraperitoneally.

ONC injury model. ONC was performed as previously described $(5,8)$. To approach the optic nerve, an incision to the conjunctiva was made on the right eye with the guidance of a binocular-operating microscope. The optic nerve was exposed following separation of the retractor bulbi muscle. The crush was performed at $2 \mathrm{~mm}$ posterior the eyeball for $9 \mathrm{sec}$ with a Sugita Titanium Aneurysm Clip II Applier (Mizuho Medical Co., Ltd, Tokyo, Japan). Care was taken to avoid affecting the retinal blood supply. An antibiotic ophthalmic ointment was applied to the models after surgery. The sham group received optic nerve exposure without the crush.

CO preconditioning. To examine the neuroprotective effect of inhaled $\mathrm{CO}$, animals were randomized to receive treatment either with air, or air supplemented with 250 ppm CO (Shanghai Baosteel Gases Co., Ltd., Shanghai, China) for $1 \mathrm{~h}$ in an air-sealed chamber prior to ONC. The temperature in the chamber was maintained within the range of $22-25^{\circ} \mathrm{C}$. During this procedure, the animals were awake and freely moving in the chamber. Anesthesia was performed (the procedure lasted $\sim 10 \mathrm{~min}$ ) immediately following gas inhalation, following the ONC approach.

Hematoxylin and eosin $(H \& E)$ staining. At 1 and 2 weeks post-surgery, six rats in each group were euthanized with excessive anesthesia and $\mathrm{CO}_{2}$ inhalation. The eyeballs were dissected and fixed in $1 \%$ glutaraldehyde and $4 \%$ paraformaldehyde (PFA) in $0.1 \mathrm{M}$ PBS overnight at $4^{\circ} \mathrm{C}$. Then the entire eyeballs were paraffin-embedded. H\&E staining was performed using standard techniques for paraffin-embedded tissues at $25^{\circ} \mathrm{C}$ for $10 \mathrm{~min}$. Sections of $4-\mu \mathrm{m}$ were cut, and three sections with the sagittal plane through the optic nerve head area were selected for each eye. The H\&E-stained retinas were imaged in 10 high power fields (HPF; magnification, $\mathrm{x} 400$ ) on a Nikon microscope (Nikon Eclipse E100; Nikon Corporation, Tokyo, Japan). Image Pro Plus software version 6.0 (Media Cybernetics, Inc., Rockville, MD, USA) was used to perform quantitative analysis of cell numbers in the retina ganglion cell layer (GCL); six fields (two inner, two mid-periphery and two outer retinal eccentricity) per eye were averaged. There were six rats in every group at each time point.

$R G C$ quantification. To evaluate the quantification of the RGCs at 2 weeks post-ONC, FluoroGold (Sigma-Aldrich; Merck $\mathrm{KGaA}$, Darmstadt, Germany) was used 2 days prior to euthanasia, as previously described (16-18). The FluoroGold was dissolved in saline and injected into the intravitreal area using a Hamilton syringe, with a final concentration of $3 \%$ in $1 \mu \mathrm{l}$ for each eyeball. At 2 weeks post-ONC, globes were removed and soaked in $4 \% \mathrm{PF}$ for $2 \mathrm{~h}$ at $4^{\circ} \mathrm{C}$. Following removal of the cornea and lens, the retinas were extracted and flattened onto microscope slides by making four radial cuts around the optic disc (19). We performed cell counting based on observation under a fluorescence microscope (Olympus BX-51; Olympus Corporation, Tokyo, Japan) at x20 magnification. A grid frame $(0.5 \times 0.5 \mathrm{~mm})$ was used to choose the sample areas. The number of RCGs was counted and the density calculated. RGCs were sampled at the inner (1/6 retinal eccentricity), mid-periphery (1/2 retinal eccentricity) and outer (5/6 retinal eccentricity) of each quadrant of the retinal flat mount (20). RGC densities were quantified by calculating the mean of the samples. There were three animals in each group.

FVEP analysis. Visual electrophysiology was measured using an FVEP analyzing instrument (BMLab 4.0; Second Military Medical University, Shanghai, China) at 1 and 2 weeks post-ONC. Following anesthesia, each animal was secured to a stereotaxic frame. Subsequent to cutting the skin and drilling a hole above the visual cortex on the skull, an active electrode was placed on the pachymeninx and a passive electrode was placed on the skin in the interorbital region. The settings were background illumination off, 25 sweeps were added up for a test in a single flash $(10 \mathrm{db} ; 1.0 \mathrm{~Hz})$. Only the latency of the first positive $(\mathrm{P})$ wavelet, and the amplitude between the first negative $(\mathrm{N})$ and $\mathrm{P}$ wavelet of FVEP, were measured and compared among the three groups. There were six rats in every group at each time point.

Terminal deoxynucleotidyl transferase (TdT) dUTP nick end labeling (TUNEL) staining. TUNEL staining was performed on the cryosections using the In Situ Cell Death Detection kit (Roche Diagnostics, Indianapolis, IN, USA). A total of 2 weeks post-surgery, eyeballs were rapidly enucleated following sacrifice and postfixed in $4 \% \mathrm{PFA}$ overnight at $4^{\circ} \mathrm{C}$. Following dehydration with sucrose, the eyes were frozen and cut into $12-\mu \mathrm{m}$ sagittal sections. Sections with the plane through the optic papilla were permeabilized with $0.1 \%$ Triton X-100 for $2 \mathrm{~min}$. The TUNEL reaction was incubated in TdT enzyme and visualized by chromogenic staining with diaminobenzidine $(10 \mathrm{mg} / \mathrm{ml})$ at room temperature for $15 \mathrm{~min}$ (Sigma-Aldrich; Merck KGaA). TUNEL-positive (dark brown staining of the diaminobenzidine) cells in the retinal GCL were analyzed in $10 \mathrm{HPF}$ (magnification, x400) and six fields were averaged for each eye. There were three animals in each group.

Caspase-9 and caspase-3 activity assay. To quantify the caspase- 9 and caspase- 3 activity among the groups, the retinal 
caspase- 9 and caspase- 3 enzymatic activity was measured using a Caspase-9 Activity Assay kit (Beyotime Institute of Biotechnology, Haimen, China) and a Caspase-3 Activity Assay kit (Beyotime Institute of Biotechnology) at 2 weeks post-surgery. Following measurement of the protein content using a protein assay kit (Beyotime Institute of Biotechnology), each sample was mixed with Ac-DEVE-pNA and reaction buffer to incubate at $37^{\circ} \mathrm{C}$ for $1 \mathrm{~h}$. The retinal caspase- 9 and caspase-3 activity was calculated as the results of the calibrated absorbance at $405 \mathrm{~nm}$ using a standard curve. There were three animals in each group for each measurement.

Statistical analysis. For all analysis, the analyzers were blinded to study group. All quantitative data are expressed as the mean \pm standard deviation. The results were analyzed by one-way analysis of variance and Tukey's post hoc multiple comparisons test. $\mathrm{P}<0.05$ was considered to indicate a statistically significant difference.

\section{Results}

Inhaled $C O$ preconditioning increases $R G C$ density after $O N C$. The decreased neuronal count in the retinal GCL following ONC was assessed by H\&E staining (Fig. 1). The cell number in the GCL of the sham group was $37.2 \pm 3.8$ cells/HPF at 1 week and $34.5 \pm 3.9$ cells/HPF at 2 weeks post-surgery (Fig. 1B and E). A sequential decline of GCL neurons was observed as early as 1 week post-crush in the models, with aggravated decline by 2 weeks following ONC (Fig. 1C and F). More H\&E-stained cells in the GCL were observed in the $\mathrm{CO}+$ crush group (Fig. 1D and G) compared with the crush-only group $(29.0 \pm 1.5$ vs. $22.0 \pm 1.2$ cells/HPF at 1 week, $\mathrm{P}<0.001$; and $22.6 \pm 3.0$ vs. $16.6 \pm 0.6$ cells/HPF at 2 weeks, $\mathrm{P}<0.01$, respectively; Fig. $1 \mathrm{H}$ ). It was apparent that preconditioning with inhaled $\mathrm{CO}$ exerted a marked rescue effect on the neurons of rat retinas following $\mathrm{ONC}$ insult.

Additionally, the RGC survival rate was assessed by FluoroGold labeling to count the surviving RGC number at 2 weeks post-ONC (Fig. 2). The average RGC density in the retinas of the sham-operated group was 3,236.2 \pm 360.0 cells $/ \mathrm{mm}^{2}$ (Fig. 2A). At 2 weeks post-crush, the RGC densities decreased to $1,216.6 \pm 306.1$ and $2,186.1 \pm 394.0$ cells $/ \mathrm{mm}^{2}$ in the crush-only group and the $\mathrm{CO}+$ crush group, respectively (Fig. 2B and C; $\mathrm{P}<0.05)$. Therefore, the RGC survival rates of the crush-only group were 48.2 and $37.6 \%$ as determined by H\&E staining and FluoroGold labeling at 2 weeks, respectively. Increasing survival rates were observed in the $\mathrm{CO}+$ crush group of 66.2 and $67.6 \%$, respectively. These results demonstrated that the RGC survival rate was increased in the $\mathrm{CO}+$ crush group compared with the corresponding crush-only group.

$C O$ preconditioning ameliorated abnormal FVEP induced by $O N C$. In order to evaluate visual function among the groups, FVEP was tested at 1 and 2 weeks post-surgery (Fig. 3). The latency of the first P wave was $106.5 \pm 8.6 \mathrm{msec}$ (sham group), $181.2 \pm 14.9 \mathrm{msec}$ (crush-only group) and $156.3 \pm 19.9 \mathrm{msec}$ (CO + crush group) (crush-only group vs. sham group, $\mathrm{P}<0.001 ; \mathrm{CO}+$ crush group vs. crush-only group, $\mathrm{P}<0.05$; $\mathrm{CO}+$ crush group vs. sham group, $\mathrm{P}<0.001$; Fig. $3 \mathrm{~A}$ and $\mathrm{C})$ 1 week post-surgery. Simultaneously, the amplitude of the
A

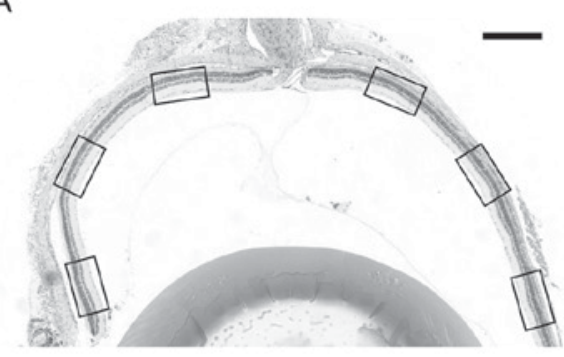

B

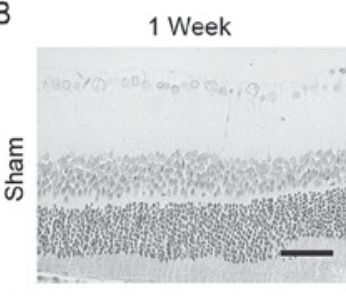

D

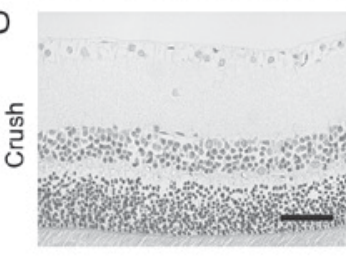

$\mathrm{F}$

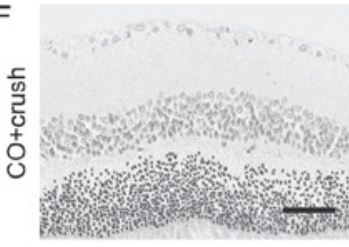

C

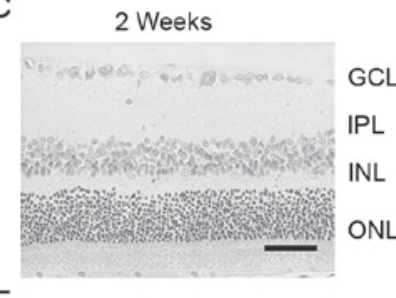

E

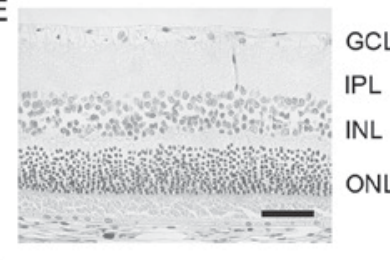

G
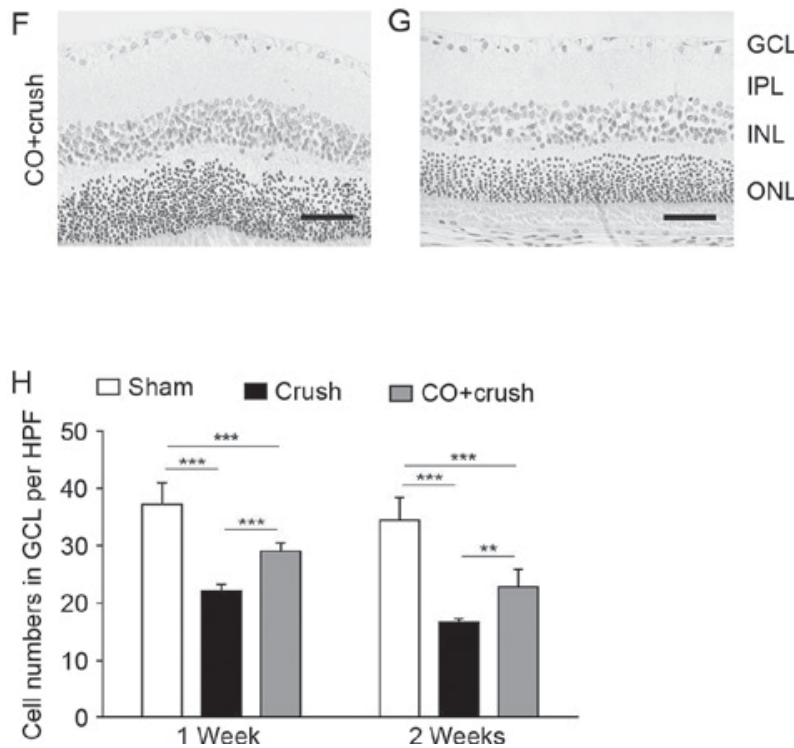

Figure 1. H\&E staining of retinas. (A) Representative image of H\&E of the retina with the optic nerve. Images were capture of the inner, mid-periphery and outer areas of the sections (scale bar, $500 \mu \mathrm{m}$ ). Representative images are presented of retinas in the (B) sham group at 1 week, (C) sham group at 2 weeks, (D) crush group at 1 week, (E) crush group at 2 weeks, (F) $\mathrm{CO}+$ crush group at 1 week and (G) $\mathrm{CO}+$ crush group at 2 weeks (scale bars, $50 \mu \mathrm{m})$. (H) The number of cells/HPF in the GCL of the $\mathrm{CO}+$ crush group was significantly increased compared with that of the crush-only group at the two time-points. ${ }^{* *} \mathrm{P}<0.01,{ }^{* * * *} \mathrm{P}<0.001 . \mathrm{n}=6$. HPF, high power field; GCL, ganglion cell layer; IPL, inner plexiform layer; INL, inner nuclear layer; ONL, outer nuclear layer; $\mathrm{H} \& \mathrm{E}$, hematoxylin and eosin.

$\mathrm{N}-\mathrm{P}$ wave was $1,035.2 \pm 162.9 \mu \mathrm{V}$ (sham group), $283.9 \pm 67.3 \mu \mathrm{V}$ (crush-only group) and 599.0 $\pm 206.5 \mu \mathrm{V}$ (CO + crush group) (crush-only group vs. sham group, $\mathrm{P}<0.001 ; \mathrm{CO}+$ crush group vs. crush-only group, $\mathrm{P}<0.01 ; \mathrm{CO}+$ crush group vs. sham group, $\mathrm{P}<0.001$; Fig. $3 \mathrm{~A}$ and $\mathrm{D}$ ). A total of 2 weeks post-surgery, the visual function had deteriorated, as demonstrated by the 

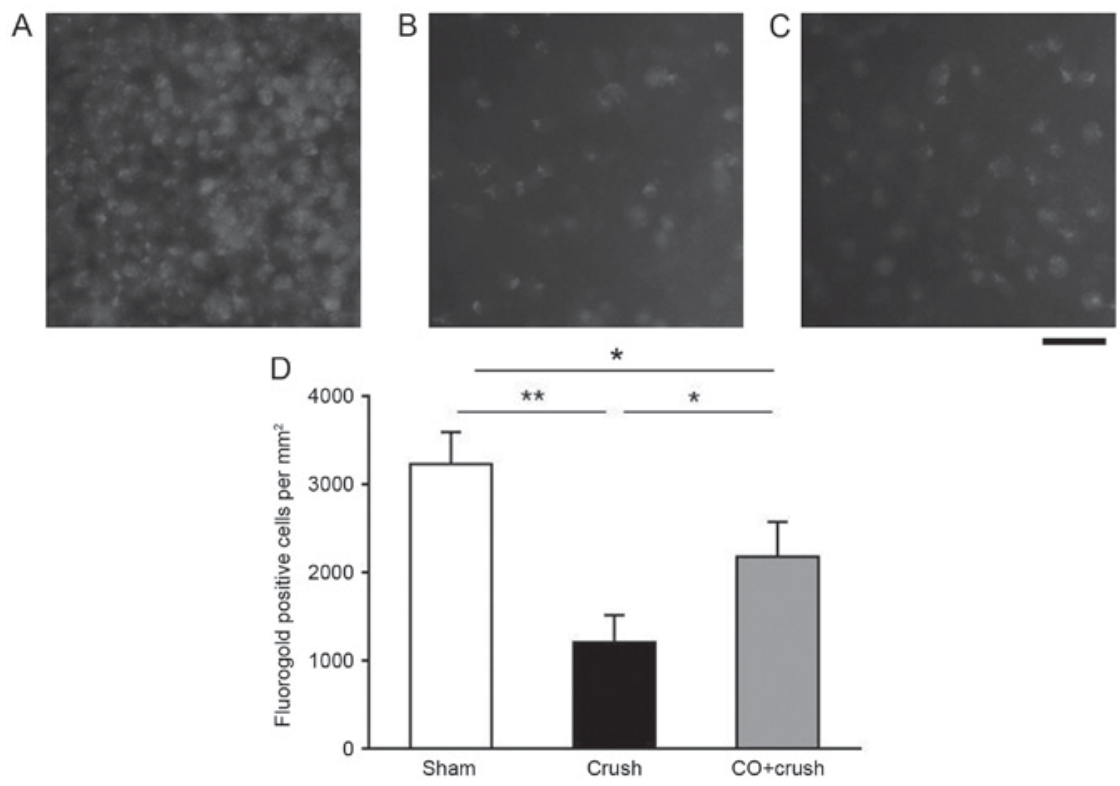

Figure 2. Representative images of flat-mounted retinas depicting FluoroGold-labeled RGCs 2 weeks post-surgery. Images are presented of (A) the sham group, (B) the crush-only group and (C) the CO + crush group. Scale bar, $50 \mu \mathrm{m}$. (D) Quantification of FluoroGold-labeled RGC number/mm ${ }^{2}$. CO preconditioning prior to crush exerted a significant neuroprotective effect. $\mathrm{P}<0.05,{ }^{* *} \mathrm{P}<0.01 . \mathrm{n}=3$. RGC, retinal ganglion cell.

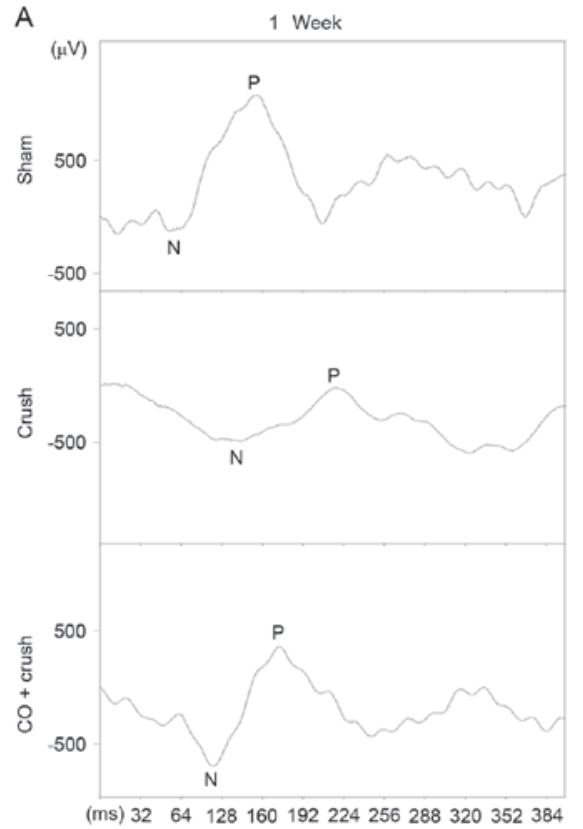

C

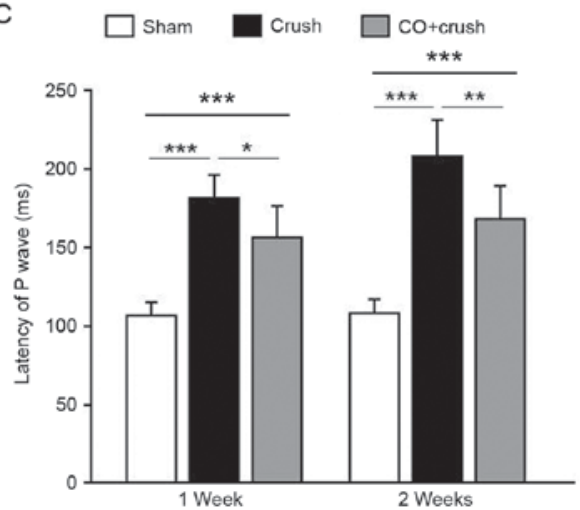

B

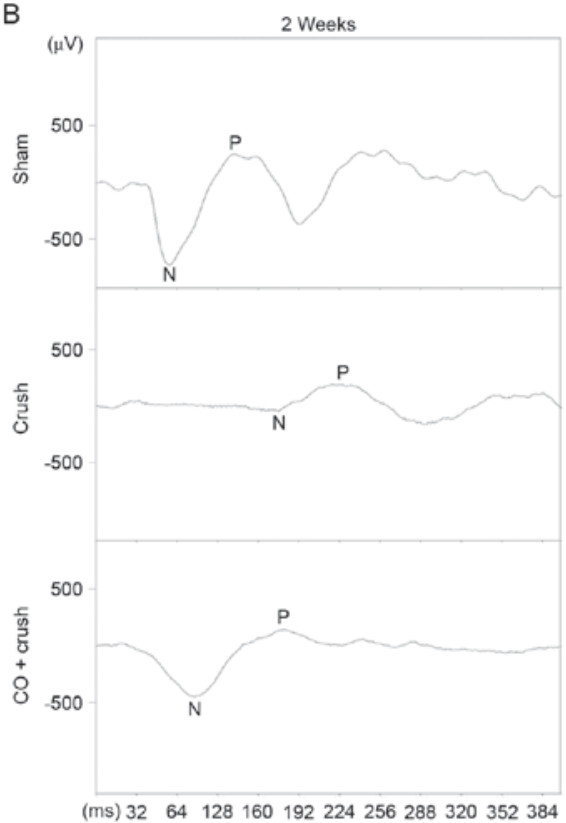

D
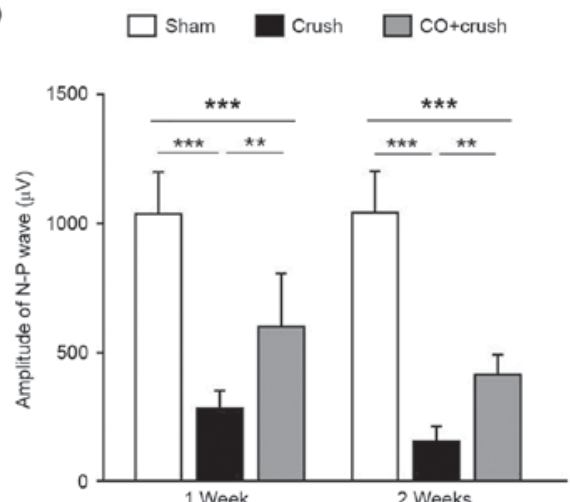

Figure 3. FVEP analysis. Representative FVEP tracings at (A) 1 week and (B) 2 weeks following surgery. (C) Latency and (D) amplitude of the P1 wave. The detection of FVEP in the $\mathrm{CO}+$ crush group exhibited a shorter latency and a higher amplitude compared with those in the crush-only group at the two time points. ${ }^{*} \mathrm{P}<0.05,{ }^{* *} \mathrm{P}<0.01,{ }^{* * *} \mathrm{P}<0.001$. $\mathrm{n}=6$. FVEP, flash visual evoked potential; $\mathrm{P}$, positive; $\mathrm{N}$, negative. 
presentation of prolonged latency $(207.8 \pm 23.2 \mathrm{msec})$ and shortened amplitude $(157.1 \pm 55.9 \mu \mathrm{V})$ in the crush-only group compared with the sham group $(108.1 \pm 8.8 \mathrm{msec}$ of latency, $\mathrm{P}<0.001$; and $1,041.6 \pm 159.1 \mu \mathrm{V}$ of amplitude, $\mathrm{P}<0.001$; Fig. 3B-D). CO preconditioning led to a shorter latency $(1,67.7 \pm 1.4$ msec; $\mathrm{P}<0.01 \mathrm{CO}+$ crush group vs. crush-only group; $\mathrm{P}<0.001 \mathrm{CO}+$ crush group vs. sham group; Fig. $3 \mathrm{~B}$ and C) and a larger amplitude $(414.1 \pm 77.0 \mu \mathrm{V} ; \mathrm{P}<0.01 \mathrm{CO}+$ crush group vs. crush-only group; $\mathrm{P}<0.001 \mathrm{CO}+$ crush group vs. sham group; Fig. 3B-D) compared with the corresponding crush-only group at 2 weeks post-surgery. These data demonstrated that $\mathrm{CO}$ preconditioning preserved visual function to a certain degree following ONC injury.

Anti-apoptotic effect of $\mathrm{CO}$ preconditioning. TUNEL staining was performed to determine the extent of apoptosis in the retina. The nuclei of cells were clearly stained and few TUNEL-positive cells were observed in sham-operated rats (Fig. 4A). As illustrated in Fig. 4B, TUNEL-positive cells were markedly increased in the GCL of the crush-only group. CO preconditioning reduced the number of TUNEL-positive cells (Fig. 4C). The TUNEL assay demonstrated that the numbers of TUNEL-positive cells/HPF in the GCL were $4.1 \pm 3.3$ cells in the sham group, $16.4 \pm 1.9$ cells in the crush-only group and $10.6 \pm 0.8$ cells in the $\mathrm{CO}+$ crush group (sham group vs. crush-only group, $\mathrm{P}<0.01$; crush-only group vs. $\mathrm{CO}+$ crush group, $\mathrm{P}<0.05$; Fig. 4D) 2 weeks following surgery, demonstrating that $\mathrm{CO}$ exerted a significant anti-apoptotic effect on RGCs following ONC.

As presented in Fig. 5, Caspase-9 and Caspase-3 Activity Assay kits were used to measure the caspase- 9 and caspase- 3 activity in the retina. The caspase- 9 activity was $0.8 \pm 0.2$, $2.8 \pm 0.4,1.8 \pm 0.3 \mu \mathrm{mol} / \mathrm{grams}$ of protein in the sham, crush-only and $\mathrm{CO}+$ crush groups, respectively $(\mathrm{P}<0.05, \mathrm{CO}+$ crush vs. crush-only group). The caspase-3 activity was $2.4 \pm 0.2,8.7 \pm 1.0$, $6.0 \pm 0.8 \mu \mathrm{mol} / \mathrm{gprot}$ in the sham, crush-only and $\mathrm{CO}+$ crush group, respectively $(\mathrm{P}<0.05, \mathrm{CO}+$ crush vs. crush-only group). The results demonstrated that the reduction of caspase- 9 and caspase- 3 activity may be involved in the mechanism of $\mathrm{CO}$-induced neuroprotection.

\section{Discussion}

The principal findings of the present study regarding inhaled CO preconditioning were as follows: i) Preconditioning significantly rescued the loss of RGCs due to ONC injury, as evidenced by the improvement in RGC density in H\&E-stained and FluoroGold-labeled flat-mounted retinas; ii) preconditioning ameliorated visual function, as demonstrated by the shortened latency of $\mathrm{P}$ waves and increased amplitude of N-P waves of FVEPs at 1 and 2 weeks post-ONC; and iii) preconditioning significantly inhibited the apoptotic process in the retina, as demonstrated by the reduction in TUNEL staining and caspase-3/9 expression. The results of the present study demonstrated that $\mathrm{CO}$ inhalation had a neuroprotective effect on RGCs in a rat ONC model.

RGCs are well-characterized CNS neurons, with the soma located in the inner part of the retina and the axon processed along the optic nerve that reach the superior colliculus in the brain $(21,22)$. The crush operation directly
A

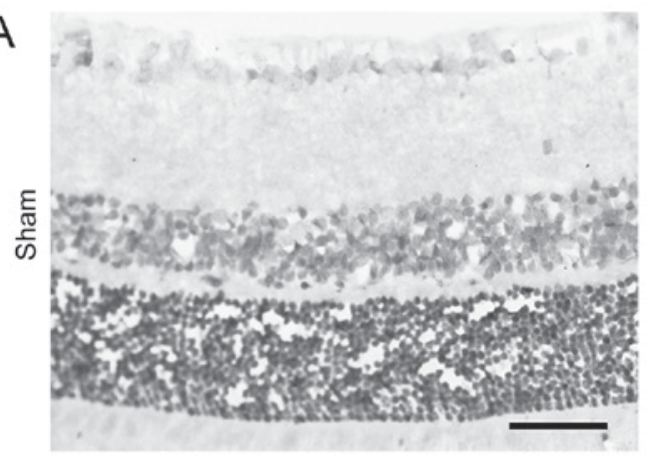

B
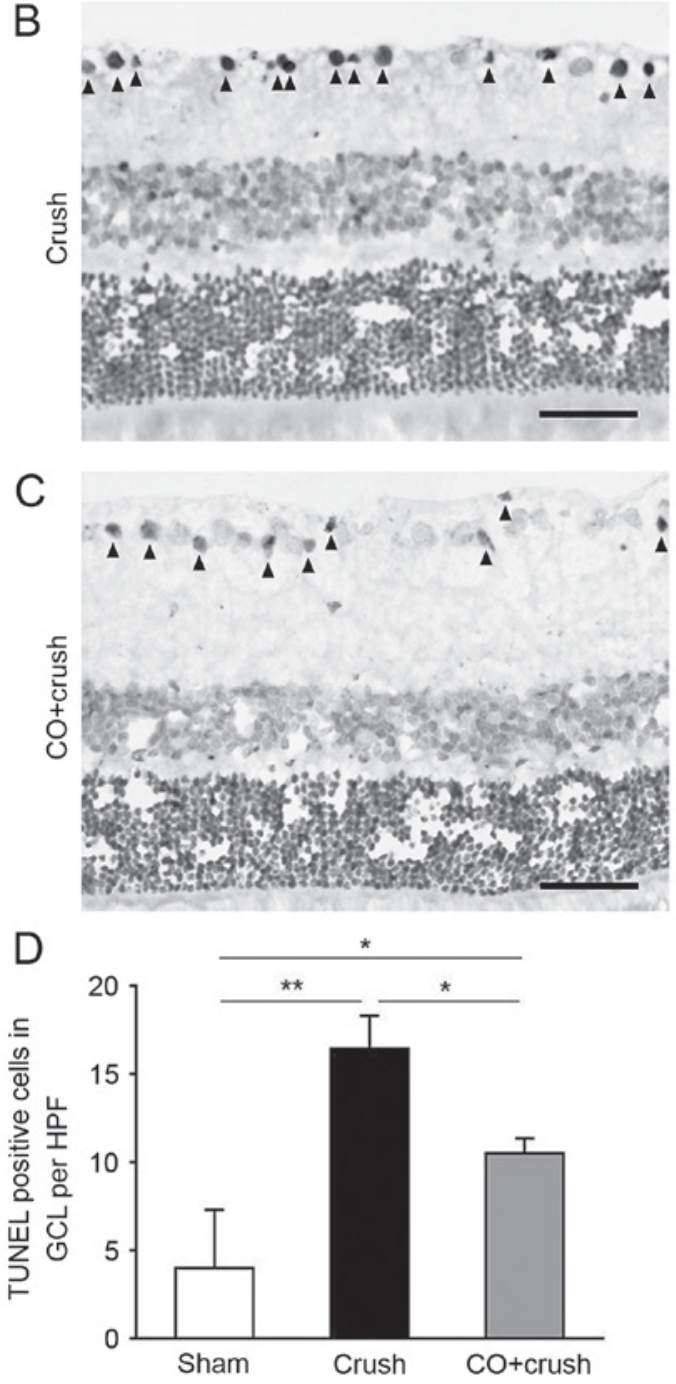

Figure 4. TUNEL staining of representative retinas at 2 weeks post-surgery. Images are presented of the (A) sham, (B) crush-only and (C) CO + crush groups. Scale bar, $50 \mu \mathrm{m}$. (D) The number of TUNEL-positive cells in the GCL of the three groups was calculated. There was a significant increase in the crush-only group compared with the sham group, and the $\mathrm{CO}+$ crush group had fewer apoptotic cells compared with the crush-only group. " $\mathrm{P}<0.05$, ${ }^{* * *} \mathrm{P}<0.01 . \mathrm{n}=3$. TUNEL, terminal deoxynucleotidyl transferase dUTP nick end labeling; GCL, ganglion cell layer; HPF, high power field.

damages the optic nerve, in addition to causing rapid injury to the RGCs (23). ONC is suitable for studying the neurodegeneration of traumatic optic neuropathy and glaucomatous damage. The development of strategies for neuroprotection in response to neuropathy has involved gaseous therapies, including $\mathrm{CO}$. 

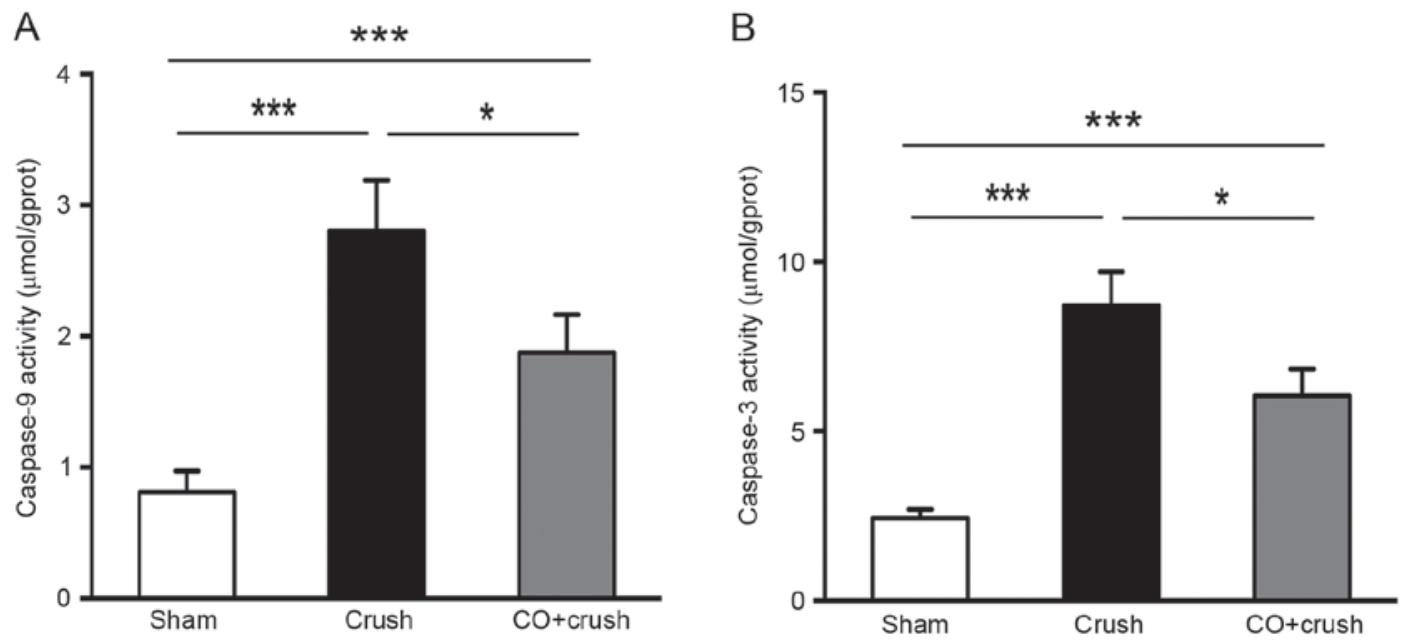

Figure 5. Caspase- 9 and caspase- 3 activity. The (A) caspase-9 and (B) caspase- 3 enzymatic activity in the retinas at 2 weeks post-surgery. The caspase- 9 and capase- 3 activity in the retinas of $\mathrm{CO}+$ crush group were significantly attenuated compared with those in the crush-only group. ${ }^{*} \mathrm{P}<0.05,{ }^{* * * *} \mathrm{P}<0.001 . \mathrm{n}=3$.

Similar to nitric oxide (NO), $\mathrm{CO}$ is regarded as a neurotransmitter and a signal molecule which mediates vasodilation, although its capacity to activate soluble guanylyl cyclase is markedly lower compared with NO (24). Inhaled $\mathrm{CO}$, in addition to $\mathrm{CO}$ donors, including $\mathrm{HO}$, or $\mathrm{CO}$ releasing molecules (CORMs), has been investigated for its potential neuroprotective effect in a number of studies. Ex vivo, $\mathrm{CO}$ derived from heme protects against amyloid $\beta$ peptide toxicity following inhibition of 5'-AMP-activated protein kinase catalytic subunit $\alpha-1$ activation, and this protective effect exists concurrently in CORM-2 in a concentration-dependent manner (25). The study of Wang et al (14) demonstrated a benefit of decreasing infarct size using $250 \mathrm{ppm} \mathrm{CO}$ inhalation immediately following permanent middle cerebral artery occlusion. In the present study, the morphological results demonstrated that inhaled CO preconditioning attenuated RGC loss due to ONC injury. In addition, FVEP measurements demonstrated that visual function was better-preserved in the $\mathrm{CO}+$ crush group compared with the crush-only group, indicating a protective effect on the ocular structures. These results indicated that $\mathrm{CO}$ preconditioning may prevent RGC damage due to $\mathrm{ON}$ injury. $\mathrm{CO}$ or its donors may be applied in sophisticated retinal or ON surgery to protect against $\mathrm{ON}$ damage. The present study was different from previous work that focused on precautions to be taken prior to neuronal injury to avoid increased damage.

The mechanisms behind low concentration $\mathrm{CO}$-induced protective effects are various. One possibility is promoting the anti-apoptotic pathway to prevent cell and tissue injury (26-28). The present study used TUNEL staining, a method involving an in situ test with TdT-specific binding to the 3'-OH ends of fragment DNA (29), to investigate the apoptotic alterations following ONC. The results of the present study suggested that the neuroprotection of $\mathrm{CO}$ preconditioning was mediated by a reduction in apoptosis of the retina in the rat model of ONC. The apoptotic pathway remains complex and poorly understood; it is considered that the caspase cascade executes this process, in which casepase- 9 is an important amplifier of the mitochondrial signaling downstream and caspase- 3 acts as the trigger of the apoptosis pathway (30). Inhibition of excessive caspase activity has been demonstrated to be neuroprotective for RGCs (31). In the present study, compared with the crush-only group, the attenuated caspase- 9 and caspase-3 expression in the $\mathrm{CO}+$ crush group demonstrated that inhaled CO preconditioning suppressed caspase- 9 and caspase-3 enzymatic activity, thereby protecting retina by mitigating apoptosis.

There are various pathways underlying $\mathrm{CO}$-mediated protection against apoptosis. Brouard et al (28) reported that $10,000 \mathrm{ppm} \mathrm{CO}$ preconditioning protected endothelial cells from tumor necrosis factor- $\alpha$-induced apoptosis by the activation of nuclear factor- $\kappa \mathrm{B}$-dependent genes, including baculoviral IAP repeat-containing protein 3 and Bcl-2 family member A1. Overexpressing heme oxygenase 1 (HO-1) had ameliorating effects on amyloid $\beta 1-42$ toxicity in Alzheimer's disease via the production of $\mathrm{CO}(25)$. Mitochondria triggered the anti-apoptotic function of mesenchymal stem cells, and inhibiting $\mathrm{HO}$ activity prevented mitochondrial biogenesis and attenuated the protective response in a co-culture of mesenchymal stem cells and distressed somatic cells (32). These beneficial effects of HO- 1 and $\mathrm{CO}$ suggested that $\mathrm{CO}$ and HO-1 may interact with each other and the underlying mechanism for its precondition neuroprotection will be explored. In addition, Abe et al (33) applied high-pressure CO in kidney transplantation and demonstrated its anti-apoptotic effects by increasing phosphatidylinositol-3 kinase and p38-mitogen-activated protein kinase. The study used mixed gas composed of $2,000 \mathrm{hPa} \mathrm{CO}$ and $1,500 \mathrm{hPa} \mathrm{O}_{2}$ to precondition the isolated kidney prior to transplantation, which led to improved renal function and tubular epithelial cellular apoptosis compared with $2,000 \mathrm{hPa} \mathrm{N}_{2}$ and 1,500 $\mathrm{hPa} \mathrm{O}_{2}$. Therefore, methods of applying $\mathrm{CO}$, and parameters including pressure and dosage, are considerations for future research.

$\mathrm{CO}$ has a primarily negative connotation as a poisonous gas, which is acknowledged so widely that working against this dogma difficult. However, $\mathrm{CO}$ gas and its molecular release have exhibited protective effects in a number of animal models (34-37). CO has also demonstrated 
benefits in suppressing proliferation and inflammation in cell cultures $(11,12)$. Being a well-known toxic gas, safety and efficacy are considerations when translating the use of $\mathrm{CO}$ to a therapeutic setting. A single-blind crossover study of 12 volunteers indicated that the increase in $\mathrm{COHb}$ level following 1,200 or 1,500 ppm $\mathrm{CO}$ administration was comparable to smoking 20 cigarettes per day, and $\mathrm{CO}$ inhalation had no significant effect on blood pressure or heart rate (38). Given that $\mathrm{CO}$ has a potent influence on the delivery of oxygen, partial pressure of oxygen and oxygen saturation were measured by Liu et al (39), and the results demonstrated that $250 \mathrm{ppm} \mathrm{CO}$ did not affect oxygenation, although $\mathrm{COHb}$ significantly increased by $5.5,2.8$ and $1.5 \%$ following $\mathrm{CO}$ saline intraperitoneal administration for 1, 3 and $6 \mathrm{~h}$ respectively. In addition, $\mathrm{CO}$ application alone did not affect intestinal cellular apoptosis. In a study of CO preconditioning with retinal ischemic/reperfusion injury, there was no difference in FluoroGold retrograde labeling RGC densities between the control group and the CO group (15). In the present study experiments, all animals were free and active during the $\mathrm{CO}$ exposure; it therefore appears that the dose of $\mathrm{CO}$ was safe for rats.

In conclusion, the results of the present study suggested that preconditioning with a low concentration $\mathrm{CO}$ inhalation provided neuroprotection following ONC, with an increased RGC survival rate, and ameliorated visual function via a caspase-dependent anti-apoptotic pathway.

\section{Acknowledgements}

The present study was supported by the General Program of Shanghai Municipal Health and Family Planning Commission (grant no. M201440522) and the National Natural Science Foundation of China (grant no. 81300777).

\section{References}

1. Sharma TP, McDowell CM, Liu Y, Wagner AH, Thole D, Faga BP, Wordinger RJ, Braun TA and Clark AF: Optic nerve crush induces spatial and temporal gene expression patterns in retina and optic nerve of $\mathrm{BALB} / \mathrm{cJ}$ mice. Mol Neurodegener 9: 14, 2014.

2. Schwartz M: Optic nerve crush: Protection and regeneration. Brain Res Bull 62: 467-471, 2004.

3. Stutzki H, Leibig C, Andreadaki A, Fischer D and Zeck G: Inflammatory stimulation preserves physiological properties of retinal ganglion cells after optic nerve injury. Front Cell Neurosci 8: 38, 2014.

4. Schmitt HM, Pelzel HR, Schlamp CL and Nickells RW: Histone deacetylase 3 (HDAC3) plays an important role in retinal ganglion cell death after acute optic nerve injury. Mol Neurodegener 9: 39, 2014.

5. Wang R, Xu J, Xie J, Kang Z, Sun X, Chen N, Liu L and $\mathrm{Xu} \mathrm{J}$ : Hyperbaric oxygen preconditioning promotes survival of retinal ganglion cells in a rat model of optic nerve crush. J Neurotrauma 27: 763-770, 2010.

6. Levkovitch-Verbin H, Harris-Cerruti C, Groner Y, Wheeler LA, Schwartz M and Yoles E: RGC death in mice after optic nerve crush injury: Oxidative stress and neuroprotection. Invest Ophthalmol Vis Sci 41: 4169-4174, 2000.

7. Bien A, Seidenbecher CI, Böckers TM, Sabel BA and Kreutz MR: Apoptotic versus necrotic characteristics of retinal ganglion cell death after partial optic nerve injury. J Neurotrauma 16: 153-163, 1999.

8. Sun JC, Xu T, Zuo Q, Wang RB, Qi AQ, Cao WL, Sun AJ, Sun XJ and $\mathrm{Xu}$ J: Hydrogen-rich saline promotes survival of retinal ganglion cells in a rat model of optic nerve crush. PLoS One 9: e99299, 2014.
9. Mansour-Robaey S, Clarke DB, Wang YC, Bray GM and Aguayo AJ: Effects of ocular injury and administration of brain-derived neurotrophic factor on survival and regrowth of axotomized retinal ganglion cells. Proc Natl Acad Sci USA 91: 1632-1636, 1994.

10. Weaver LK: Carbon monoxide poisoning. Crit Care Clin 15: 297-317, 1999.

11. Otterbein LE, Bach FH, Alam J, Soares M, Tao Lu H, Wysk M, Davis RJ, Flavell RA, Choi AM: Carbon monoxide has anti-inflammatory effects involving the mitogen-activated protein kinase pathway. Nat Med 6: 422-428, 2000.

12. Song R, Mahidhara RS, Liu F, Ning W, Otterbein LE and Choi AM: Carbon monoxide inhibits human airway smooth muscle cell proliferation via mitogen-activated protein kinase pathway. Am J Respir Cell Mol Biol 27: 603-610, 2002.

13. Brouard S, Otterbein LE, Anrather J, Tobiasch E, Bach FH, Choi AM and Soares MP: Carbon monoxide generated by heme oxygenase 1 suppresses endothelial cell apoptosis. J Exp Med 192: 1015-1026, 2000

14. Wang B, Cao W, Biswal S and Doré S: Carbon monoxide-activated Nrf2 pathway leads to protection against permanent focal cerebral ischemia. Stroke 42: 2605-2610, 2011.

15. Biermann J, Lagrèze WA, Dimitriu C, Stoykow $\mathrm{C}$ and Goebel U: Preconditioning with inhalative carbon monoxide protects rat retinal ganglion cells from ischemia/reperfusion injury. Invest Ophthalmol Vis Sci 51: 3784-3791, 2010.

16. Chen Z, Wang R, Wu J, Xia F, Sun Q, Xu J and Liu L: Low-dose carbon monoxide inhalation protects neuronal cells from apoptosis after optic nerve crush. Biochem Biophys Res Commun 469: 809-815, 2016.

17. Yang S, He H, Zhu Y, Wan X, Zhou LF, Wang J, Wang WF, Liu L and Li B: Chemical and material communication between the optic nerves in rats. Clin Exp Ophthalmol 43: 742-748, 2015.

18. Liu L, Sun Q, Wang R, Chen Z, Wu J, Xia F and Fan XQ: Methane attenuates retinal ischemia/reperfusion injury via anti-oxidative and anti-apoptotic pathways. Brain Res 1646: 327-333, 2016.

19. Vigneswara V, Berry M, Logan A and Ahmed Z: Pigment epithelium-derived factor is retinal ganglion cell neuroprotective and axogenic after optic nerve crush injury. Invest Ophthalmol Vis Sci 54: 2624-2633, 2013.

20. Mead B, Thompson A, Scheven BA, Logan A, Berry M and Leadbeater W: Comparative evaluation of methods for estimating retinal ganglion cell loss in retinal sections and wholemounts. PLoS One 9: e110612, 2014

21. Carter DA, Bray GM and Aguayo AJ: Regenerated retinal ganglion cell axons can form well-differentiated synapses in the superior colliculus of adult hamsters. J Neurosci 9: 4042-4050, 1989.

22. Osterhout JA, El-Danaf RN, Nguyen PL and Huberman AD: Birthdate and outgrowth timing predict cellular mechanisms of axon target matching in the developing visual pathway. Cell Rep 8: 1006-1017, 2014.

23. Mawrin C, Pap T, Pallas M, Dietzmann K, Behrens-Baumann W and Vorwerk CK: Changes of retinal glutamate transporter GLT-1 mRNA levels following optic nerve damage. Mol Vis 9: 10-13, 2003.

24. Barañano DE and Snyder SH: Neural roles for heme oxygenase: Contrasts to nitric oxide synthase. Proc Natl Acad Sci USA 98: 10996-11002, 2001.

25. Hettiarachchi N, Dallas M, Al-Owais M, Griffiths H, Hooper N, Scragg J, Boyle J and Peers C: Heme oxygenase-1 protects against Alzheimer's amyloid- $\beta(1-42)$-induced toxicity via carbon monoxide production. Cell Death Dis 5: e1569, 2014.

26. Wang X, Qin W, Qiu X, Cao J, Liu D and Sun B: A novel role of exogenous carbon monoxide on protecting cardiac function and improving survival against sepsis via mitochondrial energetic metabolism pathway. Int J Biol Sci 10: 777-788, 2014.

27. Nikolic I, Saksida T, Mangano K, Vujicic M, Stojanovic I, Nicoletti F and Stosic-Grujicic S: Pharmacological application of carbon monoxide ameliorates islet-directed autoimmunity in mice via anti-inflammatory and anti-apoptotic effects. Diabetologia 57: 980-990, 2014.

28. Brouard S, Berberat PO, Tobiasch E, Seldon MP, Bach FH and Soares MP: Heme oxygenase-1-derived carbon monoxide requires the activation of transcription factor NF-kappa B to protect endothelial cells from tumor necrosis factor-alpha-mediated apoptosis. J Biol Chem 277: 17950-17961, 2002.

29. Gavrieli Y, Sherman Y and Ben-Sasson SA: Identification of programmed cell death in situ via specific labeling of nuclear DNA fragmentation. J Cell Biol 119: 493-501, 1992. 
30. Hirata H, Takahashi A, Kobayashi S, Yonehara S, Sawai H, Okazaki T, Yamamoto K and Sasada M: Caspases are activated in a branched protease cascade and control distinct downstream processes in Fas-induced apoptosis. J Exp Med 187: 587-600, 1998.

31. Seki M, Soussou W, Manabe S and Lipton SA: Protection of retinal ganglion cells by caspase substrate-binding peptide IQACRG from N-methyl-D-aspartate receptor-mediated excitotoxicity. Invest Ophthalmol Vis Sci 51: 1198-1207, 2010.

32. Mahrouf-Yorgov M, Augeul L, Da Silva CC, Jourdan M, Rigolet M, Manin S, Ferrera R, Ovize M, Henry A, Guguin A, et al: Mesenchymal stem cells sense mitochondria released from damaged cells as danger signals to activate their rescue properties. Cell Death Differ 24: 1224-1238, 2017.

33. Abe T, Yazawa K, Fujino M, Imamura R, Hatayama N, Kakuta Y, Tsutahara K, Okumi M, Ichimaru N, Kaimori JY, et al: High-pressure carbon monoxide preserves rat kidney grafts from apoptosis and inflammation. Lab Invest 97: 468-477, 2017.

34. Fagone P, Mangano K, Mammana S, Cavalli E, Di Marco R, Barcellona ML, Salvatorelli L, Magro G and Nicoletti F: Carbon monoxide-releasing molecule-A1 (CORM-A1) improves clinical signs of experimental autoimmune uveoretinitis (EAU) in rats. Clin Immunol 157: 198-204, 2015.
35. Caumartin Y, Stephen J, Deng JP, Lian D, Lan Z, Liu W, Garcia B, Jevnikar AM, Wang H, Cepinskas G and Luke PP: Carbon monoxide-releasing molecules protect against ischemia-reperfusion injury during kidney transplantation. Kidney Int 79: 1080-1089, 2011.

36. Ferrándiz ML, Maicas N, Garcia-Arnandis I, Terencio MC, Motterlini R, Devesa I, Joosten LA, van den Berg WB and Alcaraz MJ: Treatment with a CO-releasing molecule (CORM-3) reduces joint inflammation and erosion in murine collagen-induced arthritis. Ann Rheum Dis 67: 1211-1217, 2008.

37. Sato K, Balla J, Otterbein L, Smith RN, Brouard S, Lin Y, Csizmadia E, Sevigny J, Robson SC, Vercellotti G, et al: Carbon monoxide generated by heme oxygenase- 1 suppresses the rejection of mouse-to-rat cardiac transplants. J Immunol 166 : 4185-4194, 2001

38. Zevin S, Saunders S, Gourlay SG, Jacob P and Benowitz NL: Cardiovascular effects of carbon monoxide and cigarette smoking. J Am Coll Cardiol 38: 1633-1638, 2001.

39. Liu SH, Ma K, Xu XR and Xu B: A single dose of carbon monoxide intraperitoneal administration protects rat intestine from injury induced by lipopolysaccharide. Cell Stress Chaperones 15: 717-727, 2010. 